\section{Annual Session of All India Stoneware Pipes Manufacturers Association}

The All India Stoneware Pipes Manufacturers Association (AISPMA) was established in 2004 and has a membership of over 40 manufacturers. There are about 200 clay and stoneware manufacturers spread over the country; the largest number located in Andhra Pradesh and Telangana states of India, mainly because of the proximity to coal and good deposits of clay. All the manufacturers operate within the small-scale sector with a total capacity of about 300,000 tonnes per annum, whereas estimated demand for clay sewerage pipes in the country is more than 500,000 tonnes/a. Clay stoneware pipes face severe competition from piping materials such as PVC and cement concrete pipes. The technology for manufacture of clay stoneware pipes in the country is outdated and heavily labour oriented. Because of the severe competition, many units are on the verge of collapse and hence there is an urgent need for the manufacturers to unite under a single platform for development of the clay stoneware pipe industry through modernization, continuous innovation, and ultimate quality improvement. Furthermore, aggressive promotion is required for clay pipes, which are environmentally friendly with a lifespan of over 100 years due to their inherent properties of corrosion resistance and indestructibility compared to alternate materials such as PVC, HDPE and concrete pipes. Comparative studies of life cycle costs of all sewerage have proven the superiority of clay stoneware pipes making them the best choice for sewerage systems. However, the short lengths and problems associated with clay stoneware pipes have allowed alternate piping materials to make severe inroads into the dominance enjoyed by clay stoneware pipes. Therefore, it is high time that manufacturers of clay stoneware pipes wake up to this situation and take serious steps to rejuvenate the industry through modernization, improving quality and ultimately productivity, and strongly meet the challenges posed by competitive products.

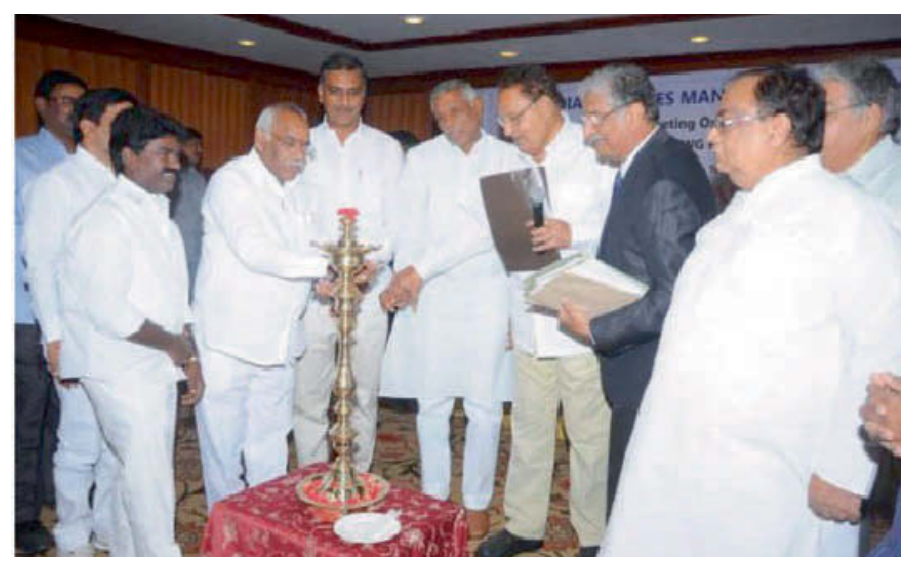

Lightening of the traditional lamp

The All India Stoneware Pipes Manufacturers Association organized their annual session on Sunday the $\mathbf{1 2}^{\text {th }}$ October 2014 at Hotel Taj Banjara, Banjara Hills, in the historic city of Hyderabad, India. The event was sponsored by Telangana SWG Pipes Manufacturers Association. Over 150 delegates attended this annual event and took active part in the discussion on the problems faced by this traditional industry.
The program commenced with an invocation by Mrs. Sudha Trivikram, followed by lighting of the traditional lamp by the Chief Guest and other dignitaries present on this occasion. The annual session was inaugurated by Mr. T. Harish Rao, Minister for Major Irrigation, Mines \& Geology, of the newly formed Government of Telangana. Sri Vara Prasada Rao, President of Telangana Stoneware Pipes Manufacturers Association and Vice President of AISPMA, welcomes the Minister and other dignitaries present.

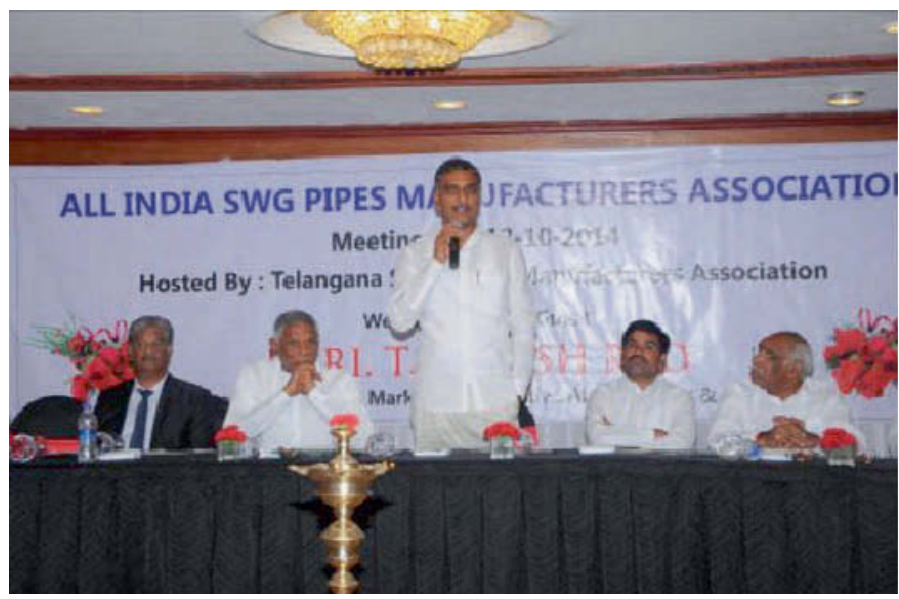

T. Harish Rao, Minister for Major Irrigation, Mines $\&$ Geology, Government of Telengana, in his inaugural speech

Mr. R.P. Trivikram, President of AISPMA, delivered his presidential address giving an overview of the clay stoneware pipe industry, and the challenges and problems faced by this traditional industry in the country. He also referred to the "Swaccha Bharat" campaign and the ambitious "Clean Ganga Mission" as National movements that have provided mega-opportunities to domestic clay stoneware pipe manufacturers by providing an efficient, low-cost wastewater disposal system with clay stoneware pipes as the best choice of piping material.

Sri T. Harish Rao assured his governments support for this traditional industry, which exports clay stoneware pipes to neighbouring states in the Southern region. The inaugural function came to an end with a vote of thanks by Sri. G. Arvind Reddy, Secretary of Telangana Stoneware Pipe Manufacturers Association.

The lively interactive post-lunch session was chaired by Dr. R.G. Shah, Ex. Chairman, Bangalore Chapter, The Indian Ceramic Society, who was assisted by Shri R.P. Trivikram. Dr. Shah invited the delegates to bring forward problems faced by the industry for discussion. The main problems faced by the clay stoneware pipe industries are efficient firing of clay pipes in Down Draft kilns using coal as a fuel, temperature variation across the kiln cross-section, delayed firing of clay pipes during the monsoon season, the cost of fuel coal against pet coke and ultimately competition from products like PVC and cement concrete pipes.

The suggestion was made to organize a seminar on energy conservation in the firing of clay stoneware pipes in DD Kilns, Chamber Kilns and Tunnel Kilns utilizing both coal and pet coke.

Finally, a two day workshop on different aspects of clay stoneware pipe manufacturing in the cluster of stoneware pipes at Mancherial for the benefit of this important industry in Telangana State was discussed.

P. Joshi and R.G. Shah, edited by L.N. Satapathy 